Neuroepidemiology 2010;34:97-98

DOI: $10.1159 / 000264827$

\section{Prediction and Prevention of Death after First-Ever Ischemic Stroke}

\section{Akiyuki Hiraga}

Department of Neurology, Chiba Rosai Hospital, Chiba, Japan

Stroke is a common cause of mortality and morbidity worldwide. Early death after stroke usually results from the direct consequences of the brain lesion itself or acute complications, whereas later death is most commonly caused by recurrent vascular events in the brain and heart [1]. This makes general management of the acute phase and prevention of recurrent stroke or cardiovascular diseases after first-ever stroke very important. Secondary prevention of recurrent stroke has been a major therapeutic advance in stroke management over the past 30 years [2]. Evidence from large randomized trials for secondary prevention of stroke has shown that it rests on the three pillars of blood pressure control, treatment of hypercholesterolemia and antiplatelet therapy [3]. Treatment of conditions that carry an increased risk of stroke, especially symptomatic carotid stenosis and atrial fibrillation, is also important. Although cases of mortality following stroke are decreasing worldwide, stroke mortality after ischemic stroke (IS) has not shown a satisfactory decline despite advances in management and secondary prevention. In fact, in 2000-2008, early case mortality for IS ranged from 13 to $23 \%$ in high-income countries, whereas it was $13-19 \%$ in low- to middle-income countries [4].

Regarding this issue, Koton and colleagues [5] report their findings on predictors of short- and long-term mortality after first-ever IS based on information from the First National Acute Stroke Israeli Survey (NASIS 2004). Using the results of a prospective national survey in 28 medical centers during February and March 2004 and collecting information on 1,079 first-ever IS patients, the authors found that the mortality following firstever IS was $9.9 \%$ at 1 month and $31.1 \%$ at 3 years. Using multivariate analysis, both short- and long-term mortality were consistently associated with age, decreased level of consciousness, severity of stroke and total anterior circulation stroke. Comorbidity - including history of dementia, diabetes, chronic heart failure, peripheral artery disease and malignancy - was positively associated only with long-term mortality. These results suggest that management of vascular risk and comorbidity is important for improvement of long-term outcomes after firstever IS.

These study results are important to understand stroke mortality in an Israeli population. Baseline information on IS mortality at the regional or national level is necessary for management of risk factors affecting mortality from IS, because rates of stroke mortality and burden vary greatly among countries [2, 4]. Geographical variations in stroke mortality may arise from differences in genetic, lifestyle or environmental factors and differences in the management of stroke. Because of these variations, stroke prevention strategies focusing on mortality risk would be most effective if focused on the regional or national level rather than worldwide. Moreover, because changes in the frequency and type of stroke may respond to changes in environment or lifestyle in various countries and regions, stroke mortality over time may vary from older to more recent reports. In addition to advances in therapeutic management, the question whether stroke mortality and predictive factors of the mortality in Israel are currently changing or are stable is important from the point of view of treatment and secondary prevention strategy. In this regard, I hope that the NASIS will be repeated within a few years.

With regard to stroke classification, the study by Koton et al. focused on the association with mortality after first-ever IS and its vascular territory, but provided less information on differences in mortality associated with subtypes of IS such as large-artery atherosclerosis and cardioembolism except for lacunar infarction (the lacunar infarction subtype is less risky). In this study, $42 \%$ of the ischemic strokes were classified as 'undetermined'. The pathophysiology of IS subtypes differs, and hence, the differences in mortality among IS subtypes are important. Understanding mortality rate differences in IS subtype incidence rates would be useful in preventing IS, especially in the management of vascular risk factors. It is my hope that the authors will investigate IS subtype differences in a future study.

We should aim to protect the patient after first-ever stroke from future events, especially stroke recurrence or other vascular events. Therefore, we need to know how to manage patients having factors predictive of long-term mortality as indicated by Koton et al. and other studies. We would like to know, for example, should patients with such predictive factors receive early treatment with potentially cardioprotective drugs (e.g. statins, angiotensin II receptor blockers or $\beta$-blockers)? In fact, a recent study from Greece showed that patients who received statins had a sig-

\section{KARGER}

Fax +41613061234 E-Mail karger@karger.ch www.karger.com
() 2009 S. Karger AG, Base

$0251-5350 / 10 / 0342-0097 \$ 26.00 / 0$ 
nificantly lower recurrence rate and lower long-term (10-year) mortality after first-ever IS [6]. In addition, the search for better drugs should be continued. To be effective, modification of factors predictive of mortality may need to be multifactorial. Understanding how to translate the predictive factors of death after first-ever IS into the prevention of stroke recurrence and other vascular events will help improve IS management strategies and outcomes in the future.

\section{References}

1 Hankey GJ: Preventable stroke and stroke prevention. J Thromb Haemost 2005;3:1638-1645.

2 Donnan GA, Fisher M, Macleod M, Davis SM: Stroke. Lancet 2008;371: $1612-1623$.

- 3 Ederle J, Brown MM: Stroke prevention. Herz 2008;33:518-523.

-4 Feigin VL, Lawes CMM, Bennett DA, Barker-Collo SL, Parag V: Worldwide stroke incidence and early case fatality reported in 56 population-based studies: a systematic review. Lancet Neurol 2009;8:355369.
5 Koton S, Tanne D, Green MS, Bornstein NM: Mortality and predictors of death 1 month and 3 years after first-ever ischemic stroke: data from the first national acute stroke Israeli survey (NASIS 2004). Neuroepidemiology 2010;34:90-96.

6 Milionis HJ, Giannopoulos S, Kosmidou M, Panoulas V, Manios E, Kyritsis AP, Elisaf MS, Vemmos K: Statin therapy after first stroke reduces 10-year stroke recurrence and improves survival. Neurology 2009;72:1816-1822.

Akiyuki Hiraga, MD

Department of Neurology, Chiba Rosai Hospital

2-16 Tatsumidai-Higashi

Ichihara-shi, Chiba 290-0003 (Japan)

Tel. +81 43674 1111, Fax +81 436741151

E-Mail hiragaa@yahoo.co.jp 